\title{
Strain Rate Sensitivity Analysis of Duplex and Superduplex Steels in Tensile Tests
}

\author{
Victor Barbosa de Souza ${ }^{a *} \mathbb{1}$, Rodinei Lopes Junior ${ }^{a}$, Paulo Feliciano Soares Filho ${ }^{b}$,
}

\author{
Heraldo Silva da Costa Mattos ${ }^{a}$
}

\author{
${ }^{a}$ Universidade Federal Fluminense - UFF, Programa Francisco Eduardo Mourão Saboya de Pós-Graduação \\ em Engenharia Mecânica - PGMEC, Rua Passo da Pátria, 153, Bloco B, 24210-240, Niterói, RJ, Brasil. \\ ${ }^{b}$ Instituto Federal de Educação, Ciência e Tecnologia Rio de Janeiro - IFRJ, Campus Paracambi, Rua \\ Sebastião de Lacerda, Centro, 26600-000, Paracambi, RJ, Brasil.
}

Received: August 25, 2019; Revised: June 07, 2020; Accepted: June 18, 2020.

\begin{abstract}
Duplex and super duplex stainless steels have high corrosion resistance, excellent mechanical properties, and high impact strength. Such characteristics make these steels able to operate in various segments of the industry, especially in aggressive environments. These alloys have higher strength than austenitic and ferritic stainless steels and their operation is generally restricted to temperatures lower than $300{ }^{\circ} \mathrm{C}$. Most steels and alloys only exhibit elasto-viscoplastic behavior at temperatures higher than $1 / 3$ of the absolute melting temperature. The objective of this work was to make an experimental study showing that the duplex and superduplex steels present a rate-dependent behavior even at room temperature (around $25^{\circ} \mathrm{C}$ ). Two different alloys: duplex stainless steel UNS 31803F51 and super duplex UNS S32760GRF55 were used in the study. Simple models were proposed to describe how the rate-dependent portion of the stress (called at this paper "the viscous term") depends on the strain rate. A simple procedure to identify experimentally all material constants that appear in the theory is presented. The experimental results are in very good agreement with the model predictions.
\end{abstract}

Keywords: Duplex and superduplex steels, Tensile tests at room temperature, Rate dependency analysis, Mechanical modeling, Parameters identification.

\section{Introduction}

Duplex and super duplex stainless steels have high corrosion resistance, excellent mechanical properties, and high impact strength. Such characteristics make these steels able to operate in various segments of the industry, especially in aggressive environments. These alloys have higher strength than austenitic and ferritic stainless steels and their operation is generally restricted to temperatures lower than $300^{\circ} \mathrm{C}$. Most steels and alloys only exhibit a rate-dependent mechanical behavior at temperatures higher than $1 / 3$ of the absolute melting temperature ${ }^{1}$.

Currently, such alloys are being used on a large scale in Brazil, mainly in petrochemical, energy, naval and oil exploration sectors. They are are used in situations where continuous production is of utmost importance, for instance, in pipes, pressure vessels, heat exchangers, reactors, pumps operating in aggressive corrosion environments. Many studies have been performed about microstructural and metalurgical aspects of these alloys (weldability, aging, heat treatments, phases, etc. for instance see $e^{2-12}$, but only a few about the phenomenological aspects of the macrossopic mechanical behavior, mainly concerned with Finite Element simulations $^{9,10}$. It is not the goal of the present paper to perform an extensive review of these studies, but the previously mentioned references give a reasonable idea of the research in thie area.

*e-mail: victor_souza11@hotmail.com
The objective of this work was to perform an experimental investigation showing that the duplex and superduplex steels present a rate-dependent behavior even at room temperature. UNS 31803F51 (duplex) and UNS S32760GRF55 (super duplex) stainless steel UNS 31803F51 and super duplex UNS S32760GRF55 used at room temperature in oil and gas industry were analysed in the present study. Tensile tests were performed ay $25{ }^{\circ} \mathrm{C}$ using different controlled strain rates. Although the proportional limit and rupture stress vary with the loading rate, the elastic properties are not significantly affected, which characterizes an elasto-viscoplastic rather than elasto-plastic behavior (the behavior would be rate-independent, even after the yielding limit) or viscoelastic (the elastic properties would also be affected by the loading rate) $)^{13}$.

Monotonic tensile tests performed under different prescribed strain rates show how the strain-strain curve is significantly affected by the loading rate. As the prescribed strain rate decreases, this curve tends towards a lower "limit curve" and, as the prescribed strain rate increases, the curve may tend to an upper limit.

A more adequate understanding of the rate-dependent behavior of these alloys would allow a safer and more reliable design of mechanical components and structures. Thus, it is also proposed in this paper simple algebraic expressions (a phenomenological model) to describe the rate-dependent portion of the stress (referred here as the "viscous term") as a 
Table 1. Chemical composition (\%) of the duplex and superduplex steels.

\begin{tabular}{ccccccccccccccccc}
\hline Material & $\mathrm{C}$ & $\mathrm{Si}$ & $\mathrm{Mn}$ & $\mathrm{P}$ & $\mathrm{S}$ & $\mathrm{Co}$ & $\mathrm{Cr}$ & $\mathrm{Mo}$ & $\mathrm{Ni}$ & $\mathrm{V}$ & $\mathrm{W}$ & $\mathrm{Cu}$ & $\mathrm{Ti}$ & $\mathrm{Nb}$ & $\mathrm{Al}$ & $\mathrm{N}$ \\
\hline UNS S31803F51 & 0.011 & 0.39 & 1.62 & 0.023 & 0.001 & 0.03 & 22.59 & 2.58 & 4.65 & 0.06 & 0.01 & 0.08 & 0.05 & 0.02 & 0.013 & 0.19 \\
\hline UNS S32760GRF55 & 0.019 & 0.31 & 0.64 & 0.025 & 0.0005 & - & 25.6 & 3.56 & 7.4 & - & 0.63 & 0.58 & - & - & - & 0.261 \\
\hline
\end{tabular}

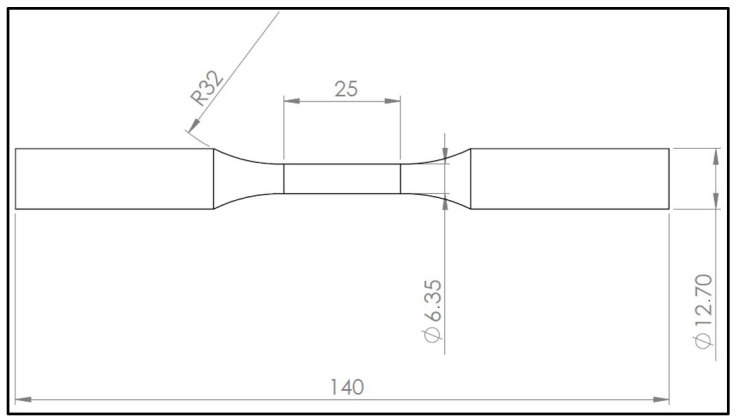

Figure 1. Test specimen dimensions ( $\mathrm{mm})$.

Table 2. Prescribed strain rates.

\begin{tabular}{cl}
\hline Material & Strain Rate \\
\hline Duplex & $1 \times 10^{-5} \mathrm{~s}^{-1}$ \\
\hline Duplex & $1 \times 10^{-4} \mathrm{~s}^{-1}$ \\
\hline Duplex & $5 \times 10^{-4} \mathrm{~s}^{-1}$ \\
\hline Duplex & $1 \times 10^{-3} \mathrm{~s}^{-1}$ \\
\hline Superduplex & $1 \times 10^{-5} \mathrm{~s}^{-1}$ \\
\hline Superduplex & $1 \times 10^{-4} \mathrm{~s}^{-1}$ \\
\hline Superduplex & $5 \times 10^{-4} \mathrm{~s}^{-1}$ \\
\hline Superduplex & $1 \times 10^{-3} \mathrm{~s}^{-1}$ \\
\hline
\end{tabular}

function of the strain rate. A simple procedure to identify all material constants that appear in the equations is presented. The results of tensile tests were compared with the models predictions showing a very good agreement.

\section{Materials and Experimental Procedures}

Duplex (UNS S3180F51) and superduplex (UNS S32760GRF55) stainless steels, used at room temperature in oil and gas industry were studied. The chemical compositions are presented in Table 1

Tensile monotonic tests with different prescribed constant strain rates were performed. The dimensions of the round test specimens were defined following the ASTM E606/E606M-12 standards ${ }^{14-17}$. The dimensions of the round test specimens are presented in Figure 1.

In this paper, the classical uniaxial engineering stress and engineering strain are noted, respectively, $\sigma$ and $\varepsilon$

$\sigma=\frac{F(t)}{A_{0}} \quad ; \quad \varepsilon(t)=\frac{\Delta l(t)}{l_{0}}$

where $F(t)$ is the axial force necessary to impose an elongation $\Delta l(t)$ at a given instant $t . l_{0}$ is the gauge length and $A_{0}$ the cross-section area.
The deformation was obtained experimentally in the tensile tests using a clip gage. Monotonic tests under controlled strain rate ( $\dot{\varepsilon}=\frac{d \varepsilon}{d t}$ ) have been performed using a $100 \mathrm{kN}$ capacity Shimadzu ${ }^{\circledR}$ AG-X universal mechanical testing machine. The tests followed the ASTM E606-12 standard and some procedures observed in Lima et al. ${ }^{8}$ and Palumbo et al. ${ }^{12}$. Table 2 presents the strain rates adopted in the study.

\section{Results and Discussion}

Figures 2 and 3 show the stress-strain curves of duplex and superduplex stainless steels obtained experimentally.

The curves are different for each loading rate, which shows that the mechanical behavior of both duplex and superduplex stainless steels is dependent on the strain rate. Although the proportional limit and rupture stress vary with the loading rate, the elastic properties are not significantly affected, which characterizes an elasto-viscoplastic rather than elasto-plastic behavior (the behavior would be rate-independent, even after the yielding limit) or viscoelastic (the elastic properties would also be affected by the strain rate). As the prescribed strain rate decreases, the stress vs strain curve tends towards a lower "limit curve". In this study, for practical purposes, the rate dependency was considered negligible for strain rates below $10^{-5} \mathrm{~s}^{-1}$. The curve obtained using a prescribed strain rate of $10^{-5} \mathrm{~s}^{-1}$ will be called "the limit curve".

\subsection{Preliminary model for monotonic tests with prescribed strain rate.}

In this paper, a simplified model for tensile tests in duplex and super duplex specimens at room temperature is proposed.

This model is conceived for a given range of strain rates $\dot{\varepsilon}_{\text {min }} \leq \dot{\varepsilon} \leq \dot{\varepsilon}_{\text {max }}$. It is difficult to present a precise definition of the limiting strain rates $\dot{\varepsilon}_{\text {min }}$ and $\dot{\varepsilon}_{\max }$. In the absence of a precise physical definition, it is suggested that a range from $10^{-5} \mathrm{~s}^{-1}$ to $10^{-2} \mathrm{~s}^{-1}$ be considered for the strain rate.

The stress in the tensile test is supposed to be the sum of two parts (see Equation 2). The first part is the rate independent stress $\sigma_{\text {lim }}$, corresponding to the lower limit curve obtained with very low strain rates (strain rates below $10^{-5} \mathrm{~s}^{-1}$ ). The second is a portion associated with viscous effects and noted here. $\sigma_{v}$.

$\sigma=\sigma_{\text {lim }}+\sigma_{v}$

Figure 4 shows the behavior in tensile tests with different strain rates.

By hypothesis, the strain is the sum of two portions: the elastic strain $\varepsilon^{e}$ and the plastic strain $\varepsilon^{p}$. The elastic Obehavior is linear, as shown in the Equations 3 and 4 .

$\varepsilon=\varepsilon^{e}+\varepsilon^{p}$

$\sigma=E \varepsilon^{e}$ 


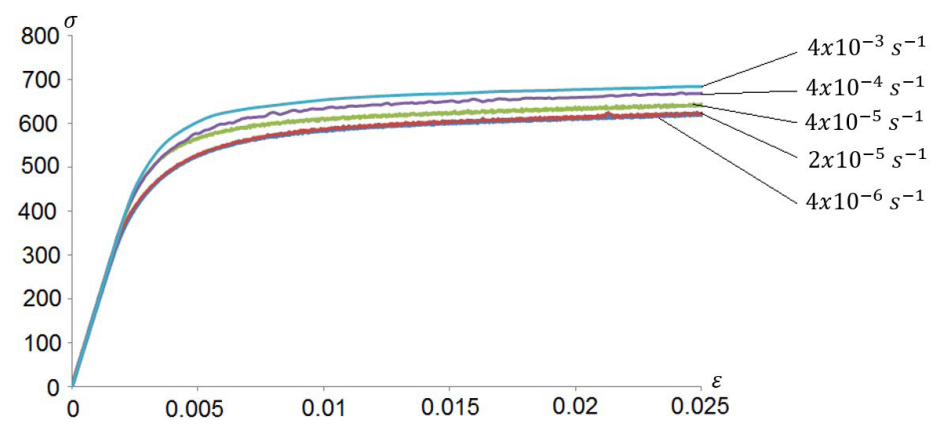

Figure 2. Experimental results of duplex stainless steel - $\sigma(\mathrm{MPa})-\varepsilon(\mathrm{mm} / \mathrm{mm})$.

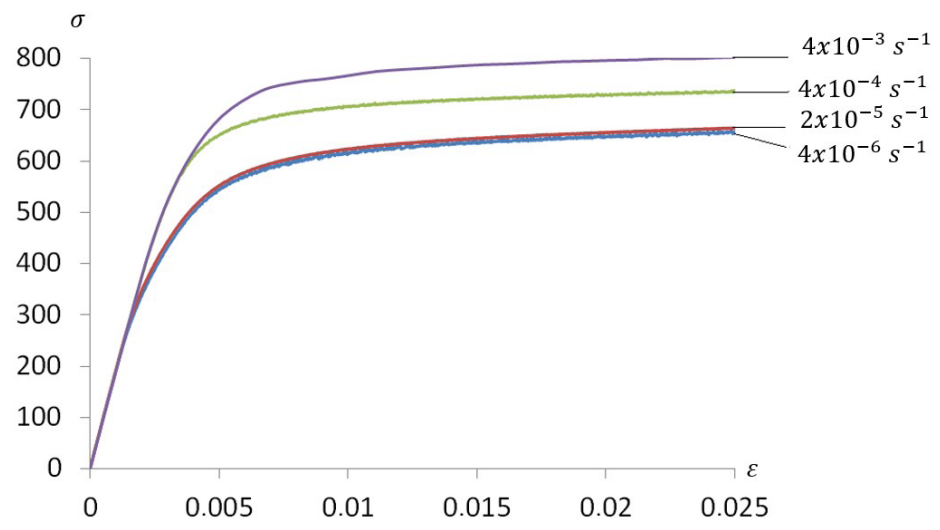

Figure 3. Experimental results of superduplex stainless steel $-\sigma(\mathrm{MPa})-\varepsilon(\mathrm{mm} / \mathrm{mm})$.

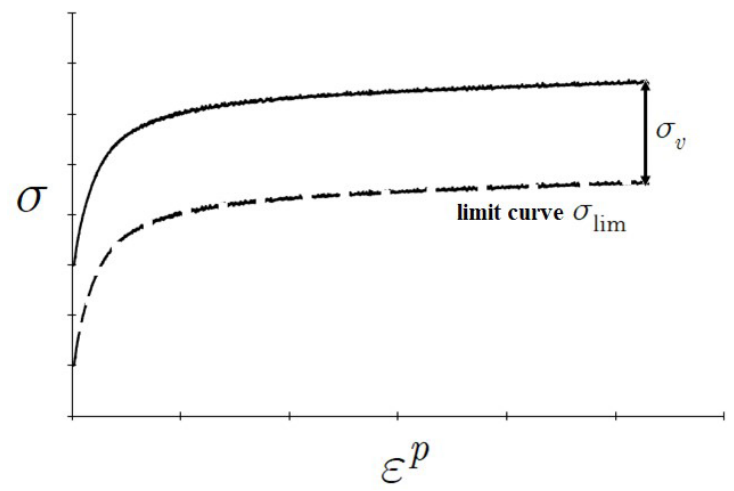

Figure 4. Tensile test with different strain rates - viscous effect.

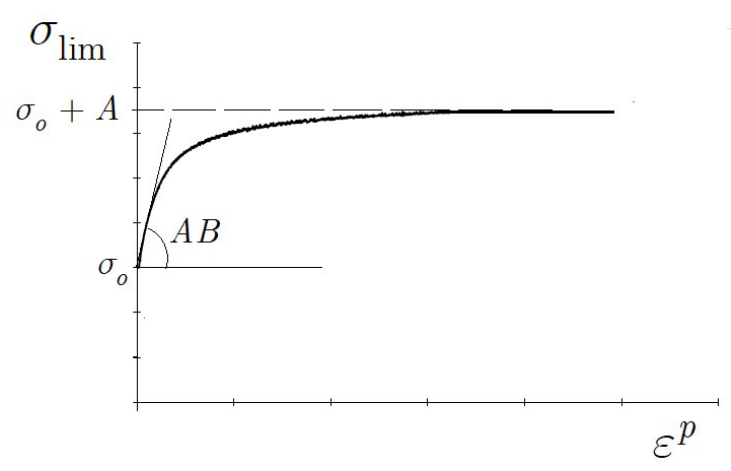

Figure 5. Schematic representation of the parameters $\sigma_{-} 0, \mathrm{~A}, \mathrm{~B}$.
Where $E$ is the modulus of elasticity.

$$
\varepsilon^{p}=\varepsilon-\varepsilon_{e}=\varepsilon-\frac{\sigma}{E}
$$

The following expression is proposed for the limit curve:

$\sigma_{\text {lim }}=\sigma_{0}+A\left(1-\exp \left(-B \varepsilon^{p}\right)\right)$

$\sigma_{0}, A, B$ are positive material constants that characterize the material and are obtained experimentally. $\sigma_{0}$ is the proportional limit obtained from the limit curve, $\left(\sigma_{0}+A\right)$ is the maximum stress in this curve and $(\mathrm{AB})$ is the slope of the curve $\sigma v s \varepsilon_{p}$ at the point $\varepsilon_{p}=0$.

$$
\lim _{\varepsilon_{p} \rightarrow \infty}\left(\sigma_{\text {lim }}\right)=\sigma_{0}+A
$$

$$
\left.\frac{d \sigma_{\text {lim }}}{d \varepsilon_{p}}\right|_{\varepsilon_{p}=0}=A B
$$

Figure 5 shows the definition of these parameters in a graph.

After determining the equation for the limit curve, it is necessary to propose an adequate expression for the term $\sigma_{v}$. Equation 9 presents the proposes expression for the viscous term

$$
\sigma_{v}=a\left(1-\exp \left(-b \dot{\varepsilon}^{p}\right)\right)
$$

$\mathrm{a}$ and $\mathrm{b}$ these are positive constants that characterize the viscosity of the material and $\dot{\varepsilon}^{p}$ is the rate of plastic deformation. It is important to note that this model has a maximum value for the viscous term as can be observed from Equation 9. 
$\lim _{\varepsilon_{p} \rightarrow \infty}\left(\sigma_{v}\right)=a$

This is in agreement with the experimental observations made in the previous section. However, this study is limited to small deformations and is conceived for low strain rates. An alternative expression to the viscous term defined in Equation 9 is

$\sigma_{v}=K\left(\dot{\varepsilon}^{p}\right)^{1 / N}$

Where $\mathrm{K}$ and $\mathrm{N}$ are material constants. Equation 11 is also reasonable for lower rates. All material constants in Equation 9 or 11 can be identified using least square techniques (there are free programs that make this fitting, such as Curve Expert $^{\circledR}$, for example). The following values were obtained for the duplex and superduplex stainless steels (Table 3).
Figures 6-10 show the comparison between the experimental stress-strain curve and the proposed model curve for duplex stainless steel using Equations 6 and 9.

Figures 11-14 show the comparison between the experimental stress-strain curve and the proposed model curve for superduplex stainless steel.

The model predictions are in very good agreement with the experimental results. Three tensile tests with different strain rates are sufficient to characterize all material constants. These equations can be extended to a three-dimensional context using the thermodynamic framework proposed in ${ }^{15}$.

Although it is not the goal of the present paper, it is interesting to observe that, it is possible to prove that the proposed equations are the one-dimensional version of the following general elasto-viscoplastic constitutive equations ${ }^{16,17}$

Table 3. Summary of elasto-viscoplasticity parameters of duplex and superduplex stainless steels.

\begin{tabular}{cccccccc}
\hline Material & $\boldsymbol{o}_{0}$ & $\mathrm{E}$ & $E_{p}$ & $A$ & $B$ & $a$ & $b$ \\
\hline Duplex & $333 \mathrm{MPa}$ & $178.16 \mathrm{GPa}$ & $188 \mathrm{MPa}$ & 277 & 517 & 66.82 & 4457 \\
\hline Superduplex & $298 \mathrm{MPa}$ & $156.02 \mathrm{GPa}$ & $190 \mathrm{MPa}$ & 346 & 546 & 149 & 1825 \\
\hline
\end{tabular}

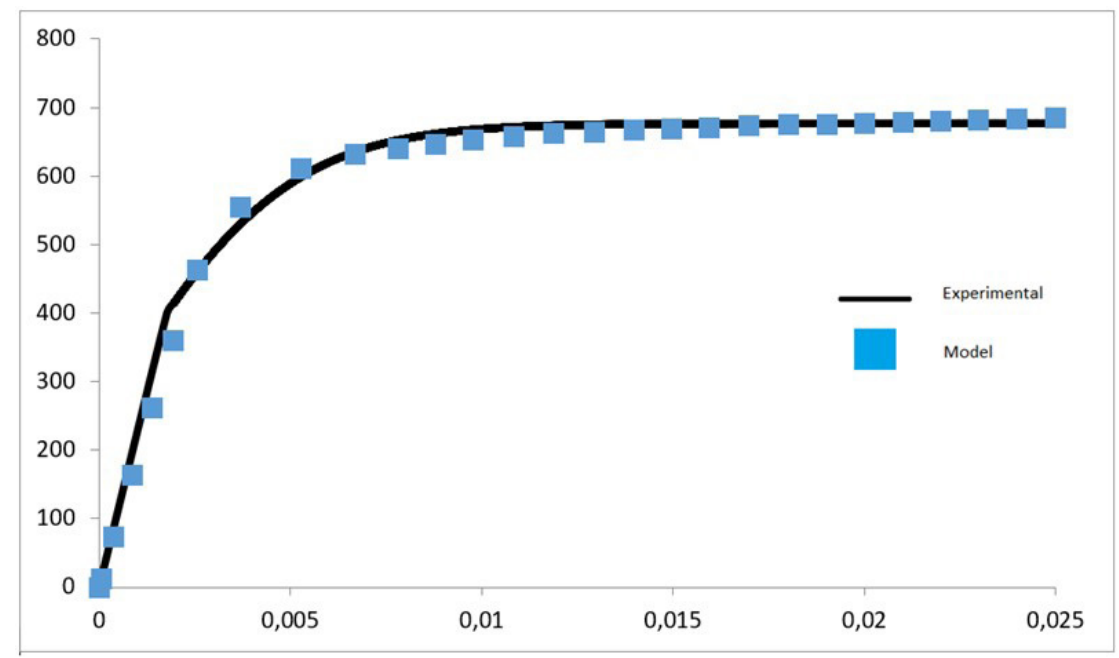

Figure 6. Comparative stress curve (MPa) - strain $(\mathrm{mm} / \mathrm{mm})-\varepsilon_{1}=4 x 10^{-6} \mathrm{~s}^{-1}$. UNS S3180F51 duplex stainless steel.

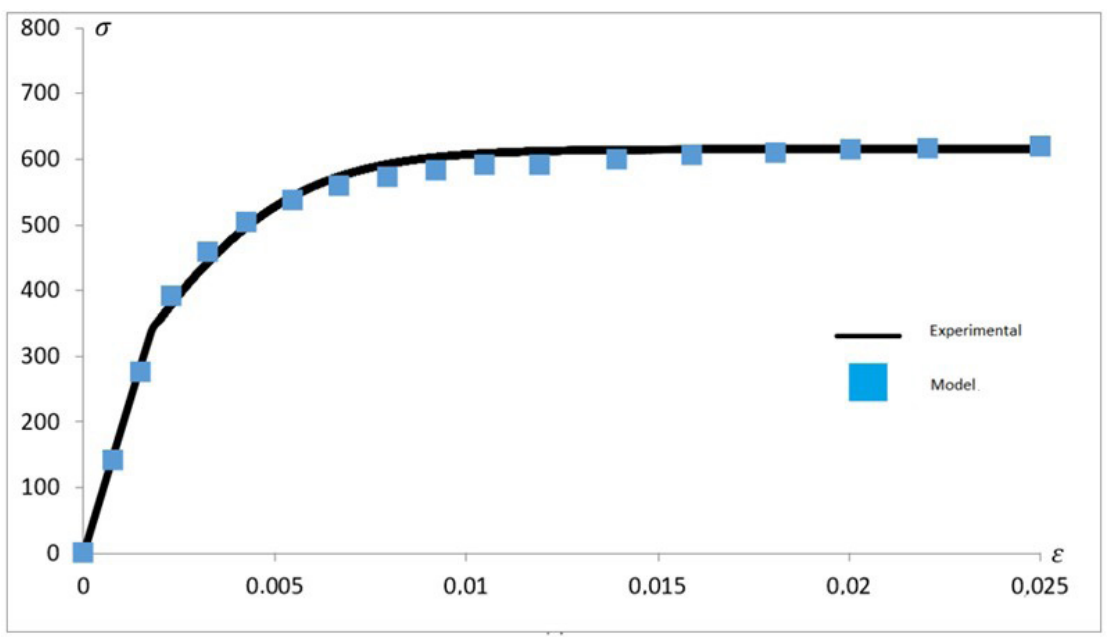

Figure 7. Comparative stress curve (MPa) - strain (mm / mm)- $\varepsilon_{2}=2 \times 10^{-5} \mathrm{~s}^{-1}$. UNS S3180F51 duplex stainless steel. 


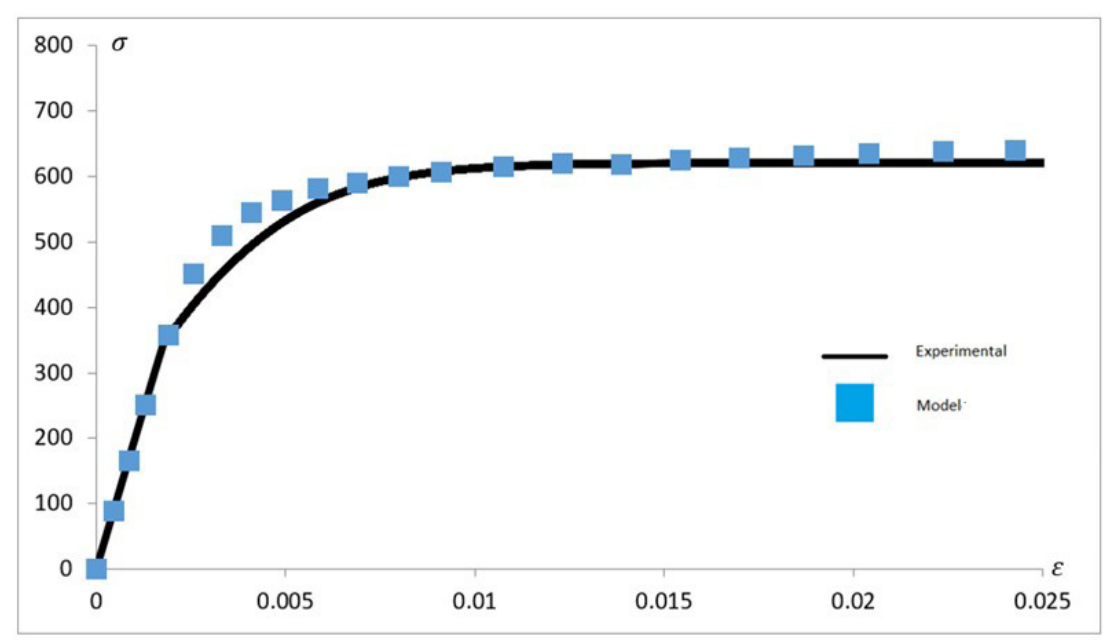

Figure 8. Comparative stress curve (MPa) - strain $(\mathrm{mm} / \mathrm{mm})-\varepsilon_{-} 3=\left[4 \times 10 \rrbracket^{\wedge}(-5) \mathrm{s}^{\wedge}(-1)\right.$. UNS S3180F51 duplex stainless steel.

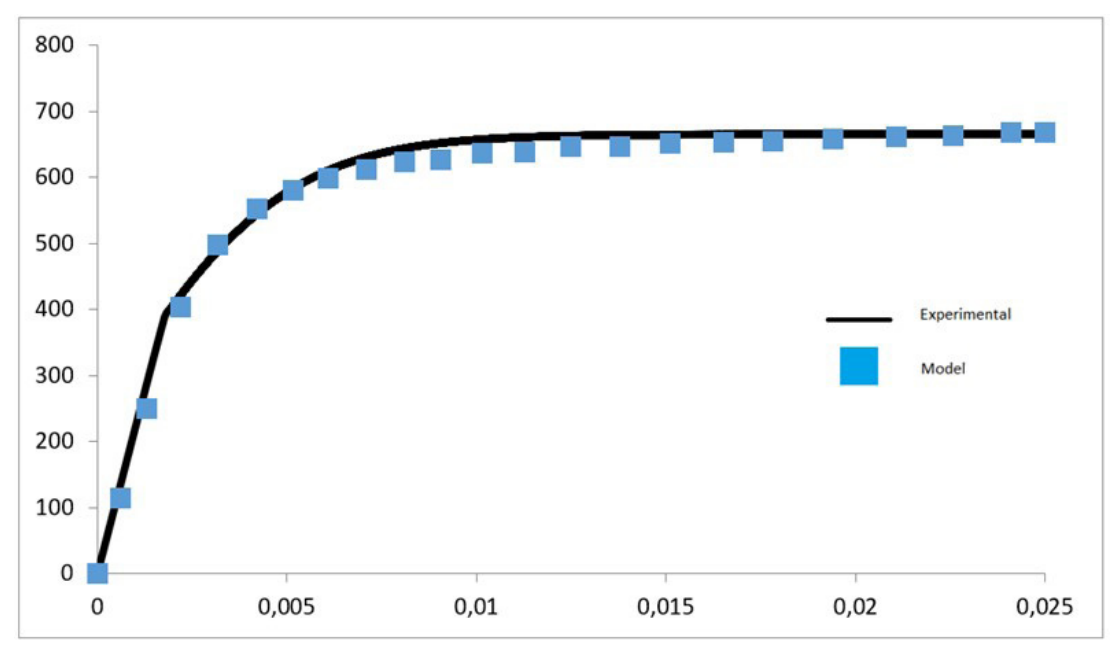

Figure 9. Comparative stress curve (MPa) - strain $(\mathrm{mm} / \mathrm{mm})-\varepsilon_{4}=4 \times 10^{-4} \mathrm{~s}^{-1}$. UNS S3180F51 duplex stainless steel.

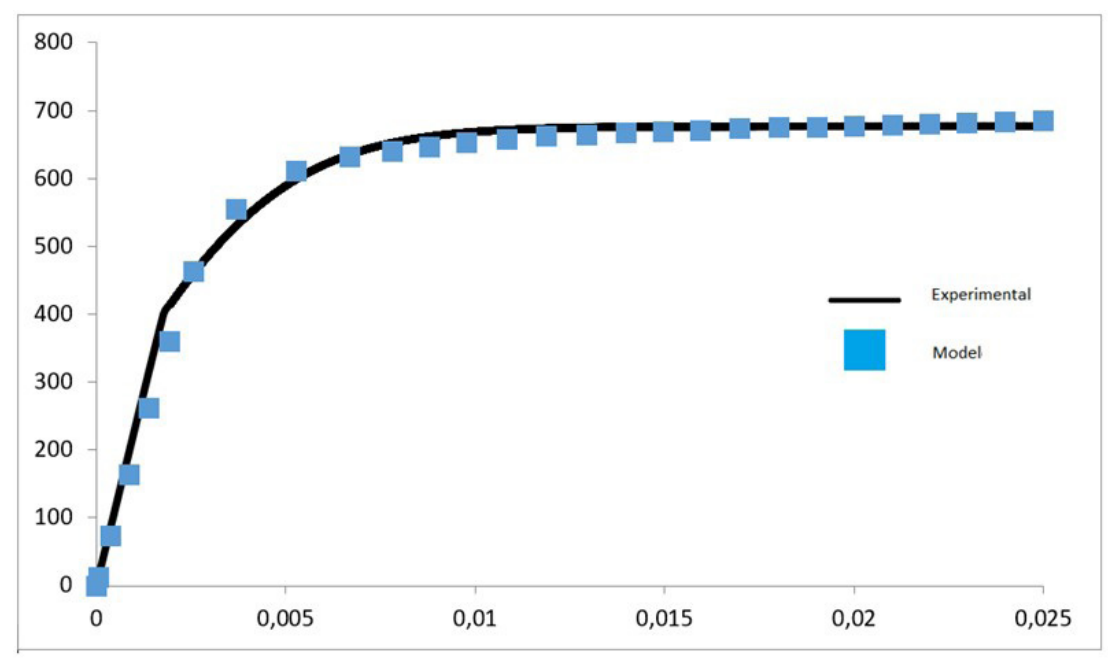

Figure 10. Comparative stress curve (MPa) - strain $(\mathrm{mm} / \mathrm{mm})-\varepsilon_{5}=4 \times 10^{-3} \mathrm{~s}^{-1}$. UNS S3180F5 duplex stainless steel. 


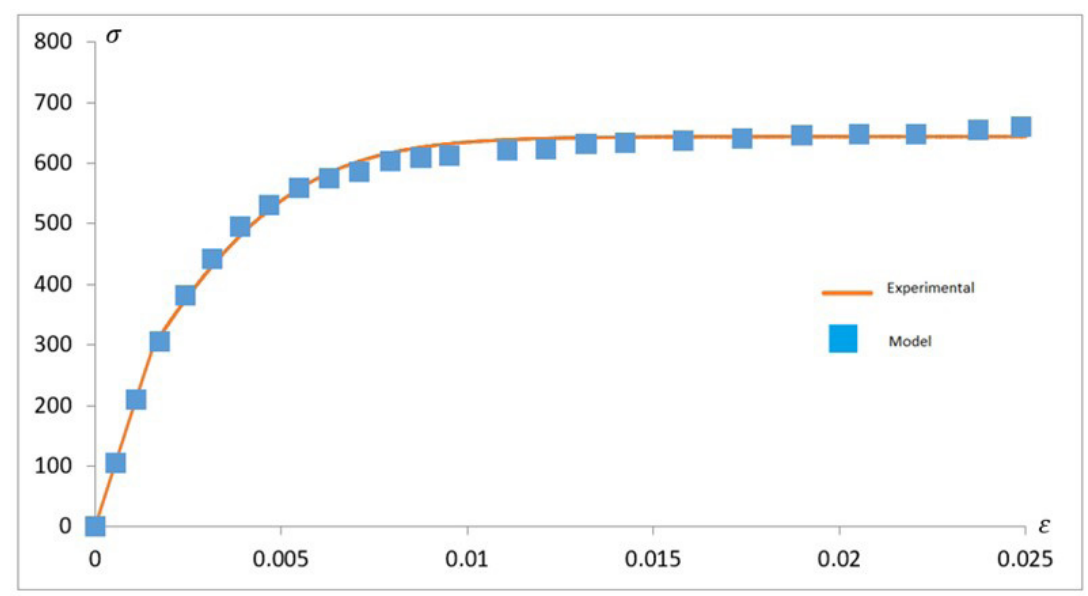

Figure 11. Comparative stress curve (MPa) - strain $(\mathrm{mm} / \mathrm{mm})-\varepsilon_{-} 1=\llbracket 4 \times 10 \rrbracket^{\wedge}(-6) \mathrm{s}^{\wedge}(-1)$. UNS S32760GRF55 super duplex stainless steel.

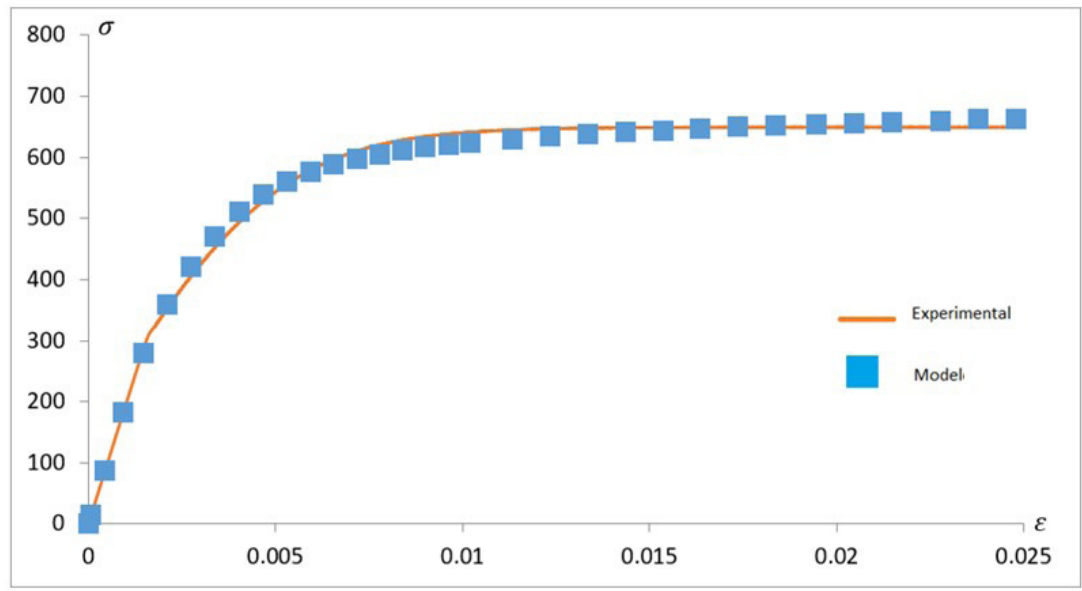

Figure 12. Comparative stress curve (MPa) - strain $(\mathrm{mm} / \mathrm{mm})-\varepsilon_{-} 2=\llbracket\left(2 \times 10 \rrbracket^{\wedge}(-5) \mathrm{s}^{\wedge}(-1)\right.$. UNS S32760GRF55 super duplex stainless steel.

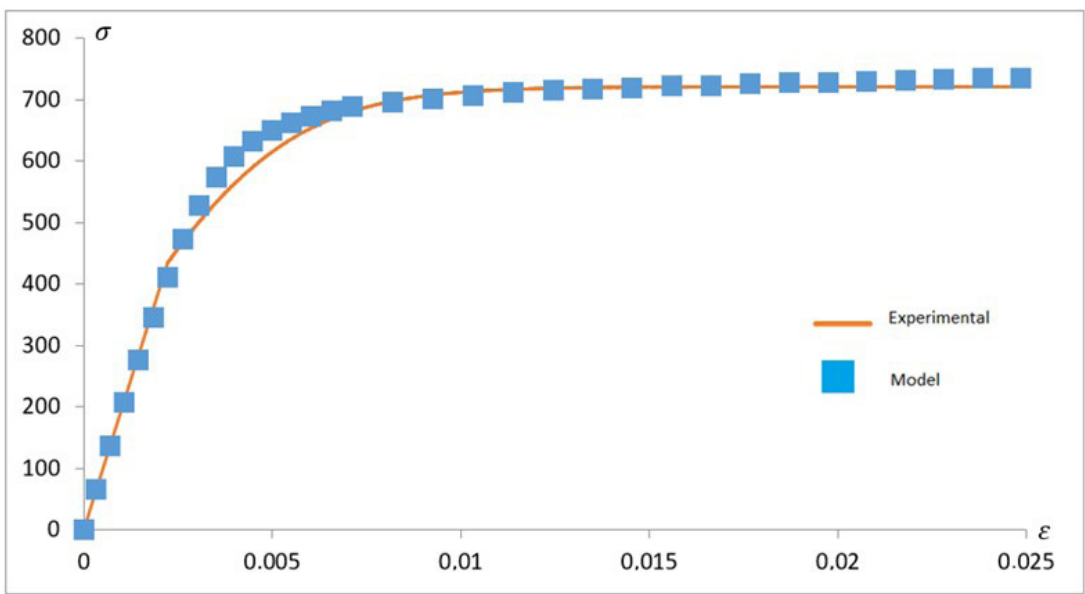

Figure 13. Comparative stress curve (MPa) - strain $(\mathrm{mm} / \mathrm{mm})-\varepsilon_{-} 4=\left[2 \times 10 \rrbracket^{\wedge}(-4) \mathrm{s}^{\wedge}(-1)\right.$. UNS S32760GRF55 super duplex stainless steel. 


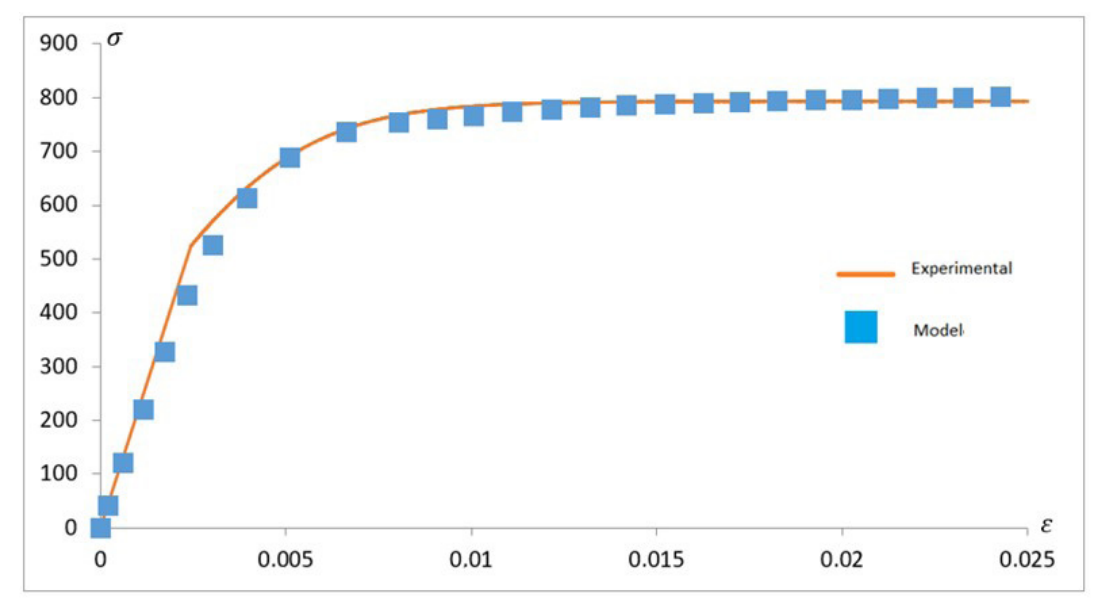

Figure 14. Comparative stress curve (MPa) - strain $(\mathrm{mm} / \mathrm{mm})-\llbracket\left[\varepsilon \_5=4 \times 10^{\wedge}(-3) \mathrm{s}^{\wedge}(-1)\right.$. UNS S32760GRF55 super duplex stainless steel.

$\underline{\sigma}=\frac{v E}{(1+v)(1-2 v)} \operatorname{tr}(\underline{\varepsilon}-\underline{\varepsilon}) \underline{\underline{\varepsilon}}+\frac{E}{(1+v)}(\underline{\varepsilon}-\underline{\varepsilon}) \Rightarrow(\underline{\varepsilon}-\underline{\varepsilon})=\frac{(1+v)}{E} \underline{\sigma}-\frac{v}{E} \operatorname{tr}(\underline{\sigma}) \underline{1}$

$\underline{\dot{\varepsilon}}^{p}=\frac{3}{2 J} \underline{S} \dot{p}$

$\dot{p}=-\frac{1}{b} \ln \left(1-\left\langle\frac{J-\sigma_{\lim }}{a}\langle\rangle\right\rangle 0\right) ;$ if Equation 9 is assumed to hold or

$\dot{p}=\left\langle\frac{J-\sigma_{\text {lim }}}{K}\langle\rangle^{N}\right\rangle ;$ if Equation 11 is assumed to hold

with

$\sigma_{\text {lim }}=\sigma_{o}+a(1-\exp (-B p))$

$J=\sqrt{\frac{3}{2}(\underline{\underline{S}}: \underline{\underline{S}})}=\sqrt{\frac{3}{2} \sum_{i=1}^{3} \sum_{i=1}^{3}\left(S_{i j}\right)^{2}}$

Where $E$ is the Young Modulus, $v$ the Poisson's ratio and $\sigma_{o}, A, B, a, b, K, N$ are positive constants that characterize the inelastic behavior of the material. The angle bracket $\langle x\rangle$ (usualy called the McCauley bracket) defined as $\langle x\rangle=\max \{0, x\}$. $\underline{\varepsilon}$ is the strain tensor. $\underline{\varepsilon}^{p}$ is the plastic strain tensor. $\underline{l}$ is the identity tensor, and $\operatorname{tr}(\cdot)$ is the trace of a tensor $(\cdot)$. $p$ is usually called the accumulated plastic strain. $\underline{\sigma}$ is the stress tensor and $\underline{S}$ is the deviatoric stress tensor given by the following expression

$\underline{S}=\left[\underline{\sigma}-\left(\frac{1}{3}\right) \operatorname{tr}(\underline{\sigma}) \underline{1}\right]$

$J$ is the von Mises equivalent stress. $\sigma_{\text {lim }}$ is an auxiliary variable related with the isotropic hardening. The anisotropy induced by the plastic deformation (kinematic hardening), which is essential for non-monotonic loading, can be included in the theory. This will be the subject of a forthcoming paper. These equations with the expression (14.2) are nothing else than the Classic Chaboche-Lemaitre elasto-viscoplastic model $^{1}$ for metals at high temperatures. However, as far as the authors know, there are no papers concerned about the elasto-viscoplastic behavior of duplex and super duplex steels at room temperature that consider expression (14.1). Curiously, the general three-dimensional constitutive equations including the kinematic hardening is very similar to the equations proposed in Motta et al..$^{18}$ for a Polyvidilene undergoing small deformations.

\section{Conclusion}

Duplex and superduplex stainless steels exhibit rate dependent behavior at room temperature $\left(25^{\circ} \mathrm{C}\right)$. The loading rate affects the plastic behavior whereas the elastic properties became unaffected.

Tensile tests performed with different prescribed strain rates in duplex stainless steel UNS 31803F51 and super duplex UNS S32760GRF55 allow observing a significant influence of the loading rate on the mechanical behavior. A simple algebraic equation is proposed to model the stress vs strain curve at different strain rates. The proposed equations are in good agreement with the experimental results.

This study is a first step towards an adequate modeling of the elasto-viscoplastic behavior of duplex and superduplex steels. Although it is not the goal of this study it is interesting 
to note that the proposed model can be generalized to a three-dimensional context. A more adequate understanding of the rate-dependent behavior of these alloys it is of great importance for a safer and more reliable design of mechanical components and structures.

\section{References}

1. Lemaitre J, Chaboche JL. Mechanichs of solid materials. Cambridge: Cambridge University; 1990.

2. Pardal JM. Effects of thermal procedures on mechanical, magnetic properties and corrosion resistance of superduplex stainless steel [thesis]. Niterói: Universidade Federal Fluminense; 2009.

3. Oliveira TS, Silva ES, Rodrigues SF, Nascimento CCF, Leal VS, Reis GS. Softening mechanisms of the AISI 410 Martensitic stainless steel under hot torsion simulation. Mater Res. 2017;20(2):395-406. http://dx.doi.org/10.1590/1980-5373mr-2016-0795.

4. Pardal JM, Tavares SSM, Fonseca MC, De Souza JA, Corte RRA, De Abreu HFG. Influence of the grain size on deleterious phase precipition in superduplex stainless steel UNS S32750. Mater Charact. 2009;60(3):165-72. http://dx.doi.org/10.1016/j. matchar.2008.08.007.

5. Haskel HL, Sanches LS, Ponte HAA. New methodology of nondestructive testing for quantitative evaluation of sigma phase in duplex stainless steels. Mater Res. 2019;22(3):e20180682. http://dx.doi.org/10.1590/1980-5373-mr-2018-0682.

6. Betini EG, Gomes MP, Mucsi CS, Orlando MTDA, Luz TS, Avettand-Fènoël M-N, et al. Effect of nitrogen addition to shielding gas on cooling rates and in the microstructure of thin sheets of duplex stainless steel welded by pulsed gas tungsten arc welding process. Mater Res. 2019;22(Suppl. 1):e20190247. http://dx.doi.org/10.1590/1980-5373-mr-2019-0247.

7. Sicupira DC, Assumpção RF, Perasoli DB, Alves DS, Ferreira AOV, Santos DB. Effect of warm rolling on the corrosion and mechanical properties of UNS S32205 duplex stainless steel. Mater Res. 2019;22(4):e20180466. http://dx.doi.org/10.1590/19805373-mr-2018-0466.

8. Lima HMLF, Bastos IN, Araujo WS, Martins M. Heat treatment effects on ASTM A890/A 890M GR 5A super duplex stainless steel passivity. Mater Res. 2017;20(Suppl. 2):775-85. http:// dx.doi.org/10.1590/1980-5373-mr-2017-0865.

9. Castro JA, Oliveira E, Almeida DSS, Fonseca GS, Xavier CR. Effects of local heat input conditions on the thermophysical properties of Super Duplex Stainless Steels (SDSS). Mater Res. 2017;20(Suppl. 1):153-61. http://dx.doi.org/10.1590/19805373-mr-2017-0384.

10. Lima MSF, Carvalho SM, Teleginski V, Pariona M. Mechanical and corrosion properties of a duplex steel welded using microarc or laser. Mater Res. 2015;18(4):723-31. http://dx.doi. org/10.1590/1516-1439.007115.

11. Tavares SSM, Pardal JM, Abreu HFG, Nunes CS, Silva MR. Tensile properties of duplex UNS S32205 and lean duplex UNS S32304 steels and the influence of short duration $475^{\circ} \mathrm{C}$ aging. Mater Res. 2012;15(6):859-64. http://dx.doi.org/10.1590/ S1516-14392012005000116.

12. Palumbo G, Piccininni A, Piglionico V, Guglielmi P, Sorgente D, Tricarico L. Modelling residual stresses in sand-cast superduplex stainless steel. J Mater Process Technol. 2015;217:253-61. http://dx.doi.org/10.1016/j.jmatprotec.2014.11.006.

13. Li H, Jiao W, Feng H, Li X, Jiang Z, Li G, et al. Deformation characteristic and constitutive modeling of 2707 hyper duplex stainless steel under hot compression. Metals. 2016;6(9):223. http://dx.doi.org/10.3390/met6090223.

14. American Society for Testing and Materials-ASTM. ASTM E6: standard test methods for tension testing of metallic materials. West Conshohocken: ASTM; 2008.

15. Mattos HSC. A contribution to the thermodynamic formulation of Elastoplasticity and Elastoviscoplasticity [thesis]. Rio de Janeiro: Pontifícia Universidade Católica do Rio de Janeiro; 1988

16. Soares PF Fo. Systematic identification of properties in elastoplasticity and cyclic elasto-viscoplasticity [thesis]. Rio de Janeiro: Universidade Federal Fluminense; 2010.

17. Souza VB. Experimental identification of elastoviscoplastic parameters of Duplex and Superduplex stainless steels [thesis]. Rio de Janeiro: Universidade Federal Fluminense; 2019.

18. Motta EP, Reis JML, Mattos HSC. Modelling the cyclic elastoviscoplastic behaviour of polymers. Polym Test. 2019;78:105991. http://dx.doi.org/10.1016/j.polymertesting.2019.105991. 